\title{
Association of KCNJ11 genetic variations with risk of Type 2 diabetes mellitus (T2DM) in North Indian population
}

Vasiuddin Khan ${ }^{\mathrm{a}^{*}}$, Deepti Bhatt $\mathrm{t}^{\mathrm{a}^{*}}$, Shahbaz Khan ${ }^{\mathrm{a}^{*}}$, Amit Kumar Verma ${ }^{\mathrm{a}}$, Rameez Hasan ${ }^{\mathrm{a}}$, Sahar Rafat ${ }^{\mathrm{a}}$, Yamini Goyal ${ }^{\mathrm{a}}$, Prahlad Singh Bharti ${ }^{\mathrm{b}}$, M.Y. Shareef ${ }^{\mathrm{c}}$, Mohammed A. Alsahli ${ }^{\mathrm{d}}$, Arshad Husain Rahmani ${ }^{\text {, }}$ Kapil Dev ${ }^{\text {a\# }}$

a-Department of Biotechnology, Jamia Millia Islamia, New Delhi

b-Department of Biophysics, All Indian Institute of Medical Sciences, New Delhi

c-Faculty of Dentistry, Jamia Millia Islamia, New Delhi

d-Department of Medical Laboratories, College of Applied Medical Sciences, Qassim University, Buraydah, Saudi Arabia

* - equal contribution

\# - corresponding author

\section{ABSTRACT}

Type 2 diabetes mellitus (T2DM) is a polygenic metabolic disease described by hyperglycemia, which is caused by insulin resistance or reduced insulin secretion. Interaction between various genetic variants and environmental factors triggers T2DM. The main aim of this study was to find the risk associated with genetic variant (rs5210) of KCNJ11gene in the development of T2D in Indian Population. A total number of 300 cases of T2D and 100 control samples were studied to find the polymorphism in KCNJ11 through PCR-RFLP. The genotype and allele frequencies in T2DM cases were significantly different from the control population. We found significant association of KCNJ11 (rs5210) gene polymorphism with T2DM in North Indian patients indicating role of this variant in developing risk for T2DM.

Keywords: Type 2 Diabetes; KCNJ11; RFLP; SNP 


\section{Introduction}

Type 2 Diabetes is a chronic metabolic disorder described by reduced insulin secretion, insulin action and elevated blood glucose. Combination of both environmental and genetic factors play prominent role in the pathogenesis of T2DM. Environmental factors include obesity, diet, physical inactivity, age, hypertension, abnormal cholesterol levels and smoking $[1]$.

As per International Diabetes Federation's (IDF) Diabetes Atlas, $8^{\text {th }}$ edition, it has been estimated that number of diabetes patients are expected to increase from 425 million in 2017 to 629 million by 2045 . India is home to 74 million people with diabetes mellitus with approximately $8.7 \%$ prevalence among adult population and considered as the "diabetes capital" of the world (IDF, $8^{\text {th }}$ edition).

Genome-wide association studies (GWAS) found various susceptibility genes for diabetes [2-4]. However, the mechanisms these genes follow for the development of diabetes is still not clear. Many gene polymorphism findings demonstrated the association of various SNPs in the pathogenesis of T2DM and in different population, each SNPs may exhibit dissimilar association with T2DM. Therefore, there is a necessity to discover various genetic risk markers/ factor of T2DM for its prevention and treatment. It has been stated that Indians may have different genetic predisposition to diabetes than Europeans [5].

In human, significance of $\mathrm{KCNJ} 11$ in insulin secretion was suggested by its function in permanent neonatal diabetes [6] and familial persistent hyperinsulinemic hypoglycaemia of infancy [7]. Insulin resistance and reduced insulin secretion together leads to T2DM development. Due to the position and function of KCNJ11 gene in regulating glucosestimulated insulin secretion, $\mathrm{KCNJ} 11$ has gained significant attention as a potential candidate for T2D susceptibility. KCNJ11 gene located at 11p15.1 on human chromosome and lacks 
intronic sequences, this gene is a member of the potassium channel gene family [8]. KCNJ11 gene encodes Kir6.2, an inward-rectifier potassium ion channel, which is 390 amino acid protein with intracellular N- and C-terminals and two transmembrane domains M1 and M2. Kir6.2 protein forms KATP channel with sulfonylurea receptor 1 (SUR1).This KATP channel, through glucose metabolism controls insulin secretion and production [9]. In this study, we evaluated the association of KCNJ11 gene variant (rs5210) with T2DM risk in North Indian patients.

\section{Results}

\subsection{Distribution of genotypes in cases and control with $\mathrm{KCNJ11}(\mathrm{A}>\mathrm{G})$ genotypes.}

We determined differences in distribution of genotype between cases and controls. From the total 300 cases, homozygous wild type (AA) was 120(40\%); heterozygous type (AG) was $136(45.3 \%)$ and homozygous mutant type (GG) was 44(14.6\%), whereas from the total 100 control samples, 58(58\%) were wild (AA); 32(32\%) were heterozygous and 10(10\%) were mutant as presented in Table 1. We observed significant difference in the dominant genotype for cases vs control (AG+GG vs AA Odd ratio=2.07 [95\% CI 1.30-3.27] p value-0.0002). These findings suggests an association between the rs5210 variant and T2DM risk in the overall analysis (AG vs. AA: $\mathrm{OR}=2.05$ [95\% CI: $1.25-3.37], p=0.0006$ ).

Table 1: Distribution of KCNJ11 genotype among cases and control

\begin{tabular}{|c|c|c|c|c|}
\hline Genotype & $\begin{array}{c}\text { Number of } \\
\text { Cases (n-300) }\end{array}$ & $\begin{array}{c}\text { Number of } \\
\text { Control (n-100) }\end{array}$ & $\begin{array}{c}\text { Odd Ratio } \\
\mathbf{( 9 5 \% C I )}\end{array}$ & P value \\
\hline $\mathrm{AA}$ & $\begin{array}{c}120 \\
(40 \%)\end{array}$ & $\begin{array}{c}58 \\
(58 \%)\end{array}$ & Ref & Ref \\
\hline $\mathrm{AG}$ & $\begin{array}{c}136 \\
(45.3 \%)\end{array}$ & $\begin{array}{c}32 \\
(32 \%)\end{array}$ & $2.05(1.25-3.37)$ & $0.0006^{*}$ \\
\hline
\end{tabular}




\begin{tabular}{|c|c|c|c|c|}
\hline GG & $\begin{array}{c}44 \\
(14.6 \%)\end{array}$ & $\begin{array}{c}10 \\
(10 \%)\end{array}$ & $2.12(0.99-4.5)$ & $0.016^{*}$ \\
\hline Carrier(AG+GG) & $\begin{array}{c}180 \\
(60 \%)\end{array}$ & $\begin{array}{c}42 \\
(42 \%)\end{array}$ & $2.07(1.30-3.27)$ & $0.0002 *$ \\
\hline
\end{tabular}

*significant at $\mathrm{p}<0.05$

2.2 Genotype distribution and Allele frequencies of KCNJ11 gene among T2D cases and controls

Allele frequencies were found to be 0.63 and 0.74 for allele $\mathrm{A}$ in cases and control respectively and for allele $\mathrm{G}$, it was 0.37 and 0.26 for cases and control respectively. The genotype and allele frequencies were significantly different from the control population .Chi square p-value obtained was 0.007 at $\mathrm{p}<0.05$ significant; Odd Ratio was 2.12 with $95 \% \mathrm{CI}$ in the range of $0.99-4.52$ as depicted in table 2.

Table 2: KCNJ11 polymorphism in T2D cases and controls

\begin{tabular}{|c|c|c|c|c|c|c|c|}
\hline \multirow[t]{2}{*}{ Population } & \multirow[t]{2}{*}{$\begin{array}{c}\text { No of } \\
\text { subjects }\end{array}$} & \multicolumn{3}{|c|}{$\begin{array}{l}\text { No of individuals }(\%) \\
\text { Genotypic frequency }\end{array}$} & \multicolumn{2}{|c|}{$\begin{array}{c}\text { Allelic } \\
\text { frequency }\end{array}$} & \multirow[t]{2}{*}{$\begin{array}{c}\text { Chi } \\
\text { square } \\
\text { test } \\
\text { P- value }\end{array}$} \\
\hline & & (AA) & $(\mathrm{AG})$ & $(\mathrm{GG})$ & $\mathrm{A}$ & G & \\
\hline $\begin{array}{c}\text { Type } 2 \\
\text { Diabetes cases }\end{array}$ & 300 & $\begin{array}{c}120 \\
(40 \%) \\
0.40\end{array}$ & $\begin{array}{c}136 \\
(45.3 \%) \\
0.45\end{array}$ & $\begin{array}{c}44 \\
(14.6 \%) \\
0.15\end{array}$ & 0.63 & 0.37 & \multirow{2}{*}{$0.007 *$} \\
\hline Controls & 100 & $\begin{array}{c}58 \\
(58 \%) \\
0.58\end{array}$ & $\begin{array}{c}32 \\
(32 \%) \\
0.32\end{array}$ & $\begin{array}{c}10 \\
(10 \%) \\
0.10\end{array}$ & 0.74 & 0.26 & \\
\hline OR & \multicolumn{7}{|c|}{2.12} \\
\hline $95 \% \mathrm{Cl}$ & \multicolumn{7}{|c|}{$0.99-4.52$} \\
\hline
\end{tabular}

*significant at $\mathrm{p}<0.05$

2.3 Comparative analysis of clinicopathological characteristics in T2D cases and control 
Various clinicopathological characteristics were compared between cases and control by using student $\mathrm{t}$-test. Significant difference was found in the mean values of Age, BMI, PPG, FPG, HbA1c, T-Cholesterol, Systolic BP, Diastolic BP and Triglycerides between cases and control, whereas no significant difference was found in HDL as depicted in table 3.

Table 3: Comparative analysis of clinicopathological characteristics in Type 2 Diabetes cases and control

\begin{tabular}{|c|c|c|c|c|}
\hline \multirow{4}{*}{ Characteristic } & \multirow{4}{*}{$\begin{array}{l}\text { T2DM } \\
(\mathrm{n}=\mathbf{3 0 0})\end{array}$} & \multirow{4}{*}{$\begin{array}{l}\text { Control } \\
(\mathrm{n}=100)\end{array}$} & \multicolumn{2}{|c|}{ t-test } \\
\hline & & & $\mathbf{t}$ & Sig. (2-tailed) \\
\hline & & & & \\
\hline & & & & P Value \\
\hline Age(Years) & $40.33 \pm 9.76$ & $35.29 \pm 7.96$ & 4.67 & $<.0001 *$ \\
\hline $\operatorname{BMI}\left(\mathrm{kg} / \mathrm{m}^{2}\right)$ & $28.8 \pm 5.22$ & $24.83 \pm 2.33$ & 7.36 & $<.0001^{*}$ \\
\hline PPG(mg/dl) & $208.5 \pm 48.49$ & $135 \pm 13.02$ & 14.96 & $<.0001 *$ \\
\hline FPG(mg/dl) & $140 \pm 35.64$ & $90.22 \pm 7.11$ & 13.86 & $<.0001 *$ \\
\hline FPI & $9.6 \pm 1.35$ & $8.66 \pm 0.71$ & 6.65 & $<.0001 *$ \\
\hline HbA1c & $7.12 \pm 1.03$ & $5.75 \pm 0.54$ & 12.72 & $<.0001 *$ \\
\hline T-Cholesterol(mg/dl) & $245.58 \pm 15.14$ & $152.63 \pm 18.82$ & 49.89 & $<.0001 *$ \\
\hline Systolic BP(mmHg) & $146.79 \pm 17.05$ & $106.07 \pm 10.39$ & 22.51 & $<.0001 *$ \\
\hline Diastolic BP (mmHg) & $102.87 \pm 16.19$ & $75.85 \pm 10.91$ & 15.55 & $<.0001 *$ \\
\hline Triglycerides(mg/dl) & $356.32 \pm 100.48$ & $140.98 \pm 5.52$ & 21.4 & $<.0001 *$ \\
\hline
\end{tabular}




\begin{tabular}{|c|c|c|c|c|}
\hline HDL-C $(\mathrm{mg} / \mathrm{dl})$ & $45.89 \pm 11.47$ & $46.21 \pm 8.7$ & 0.25 & 0.80053 \\
& & & & \\
\hline LDL-C (mg/dl) & $194.60 \pm 27.38$ & $106.42 \pm 19.92$ & 29.68 & $<.0001^{*}$ \\
\hline
\end{tabular}

Data presented as mean \pm standard deviation, ${ }^{*}$ significant at $\mathrm{p}<0.05$

\subsection{Observed and expected genotype of KCNJ11 polymorphism in control.}

Observed and expected genotype frequencies of KCNJ11 gene polymorphism in controls showed no deviation from Hardy-Weinberg equilibrium expectations. Chi square test demonstrated that there was no significant deviation Hardy-Weinberg equilibrium for KCNJ11 SNP genotypes $(\mathrm{P}>0.05)$ as shown in table 4.

Table 4: Observed and expected genotype of KCNJ11 polymorphism in control.

\begin{tabular}{|l|c|c|c|c|}
\hline Genotype & $\begin{array}{c}\text { Observed } \\
\text { Genotype }\end{array}$ & $\begin{array}{c}\text { Expected } \\
\text { Genotype }\end{array}$ & P-Value & $\begin{array}{c}\text { Chi } \\
\text { Square(X) }\end{array}$ \\
\hline AA & 58 & 54.76 & & \\
\cline { 1 - 2 } & 32 & 38.48 & 0.24222 & 2.836 \\
\hline GG & 10 & 6.76 & & \\
\hline
\end{tabular}

\subsection{Clinicopathological characteristic of Type 2 Diabetes patients among wild and} carrier alleles of KCNJ11 gene

We analysed the Clinicopathological data with carrier (AG+GG) and found out that there is no statistically significant association between the carrier allele with age (p-value-0.138), BMI (p-value-0.771), PPG (p-value-0.051), HB1Ac (p-value-0.622), Cholesterol (p-value0.081), Systolic BP (p-value-0.215), Diastolic BP (p-value-0.170), HDL (p-value-0.525) and 
Triglyceride ( $p$-value-0.422). Positive correlation was observed between FPG (p-value0.002), FPI (p-value-0.012) and LDL (p-value-0.034) with Carrier allele (AG+GG) as shown in table 5 (the result is significant at $\mathrm{P}<0.05$ ).

Table 5: Clinicopathological characteristic of Type 2 Diabetes patients

\begin{tabular}{|c|c|c|c|c|c|}
\hline \multicolumn{2}{|c|}{ Characteristic } & Total & $\mathbf{A A}$ & Carrier & P Value \\
\hline \multirow{2}{*}{ Age } & $\leq 45$ & 181 & 76 & 105 & \multirow{2}{*}{0.138} \\
\hline & $>45$ & 119 & 44 & 75 & \\
\hline \multirow{2}{*}{ BMI } & $\leq 25$ & 86 & 34 & 52 & \multirow[b]{2}{*}{0.771} \\
\hline & $>25$ & 214 & 86 & 128 & \\
\hline \multirow[b]{2}{*}{ FPG } & $\leq 140$ & 177 & 83 & 94 & \multirow{2}{*}{$0.002 *$} \\
\hline & $>140$ & 123 & 37 & 86 & \\
\hline \multirow[b]{2}{*}{ PPG } & $\leq 208$ & 170 & 76 & 94 & \multirow{2}{*}{0.051} \\
\hline & $>208$ & 130 & 44 & 86 & \\
\hline \multirow[b]{2}{*}{ HBA $1 \mathrm{C}$} & $\leq 7$ & 190 & 74 & 116 & \multirow{2}{*}{0.622} \\
\hline & $>7$ & 110 & 46 & 64 & \\
\hline \multirow{2}{*}{ Systolic BP } & $\leq 147$ & 128 & 46 & 82 & \multirow{2}{*}{0.215} \\
\hline & $>147$ & 172 & 74 & 98 & \\
\hline \multirow{2}{*}{ Diastolic BP } & $\leq 103$ & 206 & 77 & 129 & \multirow{2}{*}{0.170} \\
\hline & $>103$ & 94 & 43 & 51 & \\
\hline \multirow[b]{2}{*}{ Cholesterol } & $\leq 245$ & 190 & 83 & 107 & \multirow{2}{*}{0.081} \\
\hline & $>245$ & 110 & 37 & 73 & \\
\hline
\end{tabular}




\begin{tabular}{|l|l|l|l|l|l|}
\hline \multirow{2}{*}{ FPI } & $\leq 9.6$ & 176 & 60 & 116 & \multirow{2}{*}{$0.012^{*}$} \\
\cline { 2 - 5 } & $>9.6$ & 124 & 60 & 64 & \\
\hline \multirow{4}{*}{ Triglyceride } & $\leq 355$ & 154 & 65 & 89 & \multirow{2}{*}{0.422} \\
\cline { 2 - 5 } & $>355$ & 146 & 55 & 91 & \\
\hline \multirow{2}{*}{ HDL-C } & $\leq 46$ & 189 & 73 & 116 & \multirow{2}{*}{0.525} \\
\cline { 2 - 5 } & $>46$ & 111 & 47 & 64 & \\
\hline \multirow{2}{*}{ LDL-C } & $\leq 195$ & 93 & 43 & 50 & \multirow{2}{*}{$0.034 *$} \\
\cline { 2 - 6 } & $>195$ & 207 & 65 & 130 & \\
\hline
\end{tabular}

*significant association at $p<0.05$

\section{Discussion}

In the present case-control study, we investigated association of SNP (rs5210) within the KCNJ11 gene with the susceptibility to T2D in the North Indian origin patients. KCNJ11 polymorphism association with $\mathrm{T} 2 \mathrm{D}$ risk has been extensively studied in European population however; their relationship in Indian subcontinent is yet to be validated.

In the present study, we observed a significant difference in the distribution of KCNJ11 genotypes among T2DM cases and healthy controls, higher mutant allele distribution was observed among cases as compared to healthy controls. Our findings indicated an association between KCNJ11 (rs5210) gene polymorphism with T2DM in North Indian patients. We also compared means of clinicopathological characteristics between cases and control and observed significant difference in all the parameters except HDL. In our study Clinicopathological data with carrier allele $(\mathrm{AG}+\mathrm{GG})$ was also analysed and found out that there is no statistically significant association between the carrier allele with age, BMI, PPG, HB1Ac , HDL, Systolic BP, Diastolic BP, Cholesterol and Triglyceride, whereas positive correlation was observed between FPG, LDL, FPI with Carrier allele. 
Our findings was found to be similar with other studies which confirmed the association of KCNJ11 variant $3 p+215($ rs5210) with T2D [10, 11]. Another meta-analysis study also demonstrated significant association of variants of KCNJ11 such as rs5219, rs5210, and rs5215 with T2D [12]. Similarly, meta- analysis in East Asian population, genotypic and allelic contrast also suggested significant association of KCNJ11 and T2D for rs5210 [13].Furthermore, rs5210 variant of KCNJ11 gene was indicated to be related with T2DM risk in meta-analysis of 5 studies and it was significantly heterogeneous $(p=0.02)[12]$. Similar results were also observed in Mexican, Finnish and Korean population [14-16]. A study conducted in South Indian population of Hyderabad suggested an association between KCNJ11 polymorphism in T2DM susceptibility [17], which was consistent with our findings.

Our results were found to be inconsistent with other studies in which no association was found between KCNJ11 E23K polymorphism and T2D in Iranian population [18] , Czech population [19] and Moroccan population [20]. Similarly, another study also suggested that genetic variant of KCNJ11 did not show any significant association with T2DM risk in Mongolian population $(\mathrm{OR}=1.07 ; \mathrm{P}=0.645)$ [21].

Genetic determinates will enable us to find the risk prediction of T2DM development and its pathogenesis and application of individualised treatment for therapy.

\section{Materials and Methods}

\subsection{Ethical approval and study subjects}

Collection of clinical data in pretext Performa and sample collection of the diabetic subjects/patients and control/non- diabetic of North Indian origin from Ansari Health Center Jamia Millia Islamia New Delhi was done with due consent and after getting Ethical clearance from the Institute Ethical Committee, Jamia Millia Islamia, New Delhi (Proposal No. 17/9/14/JMI/IEC/2015 dated 14/01/2016). The present cohort study was conducted in 
Department of Biotechnology, Jamia Millia Islamia, New Delhi, a total of 400 samples (300 cases and 100 controls) were collected, which fulfill all the relevant selection criteria.

\subsection{Single Nucleotide Polymorphism (SNP) Genotyping by PCR-RFLP}

Genomic DNA was extracted from fresh blood using phenol chloroform method. SNP (single nucleotide polymorphism) was detected with the use of primers i.e. forward 5'ATCCAGGGTGTTACAAGGCA3' and reverse 5'-TTTCAGGGACCAAGTAGAGCTG-3'. These primers were used to exponentially amplify the316 bp of DNA fragment. PCR was performed and the conditions were as follows: Initial denaturation of $95^{\circ} \mathrm{C}$ for 5 minutes, followed by 35 cycles of $95^{\circ} \mathrm{C}$ for $30 \mathrm{sec}, 60^{\circ} \mathrm{C}$ for $30 \mathrm{sec}, 72^{\circ} \mathrm{C}$ for $30 \mathrm{sec}$ and final extension of $72^{\circ} \mathrm{C}$ for $5 \mathrm{~min}$ in PeqSTAR 96 universal gradient thermocycler (Peqlab,VWR).Amplified products were then electrophoresed on $2 \%$ agarose gel and images were then captured by gel documentation system (Biorad) as shown in Fig.1

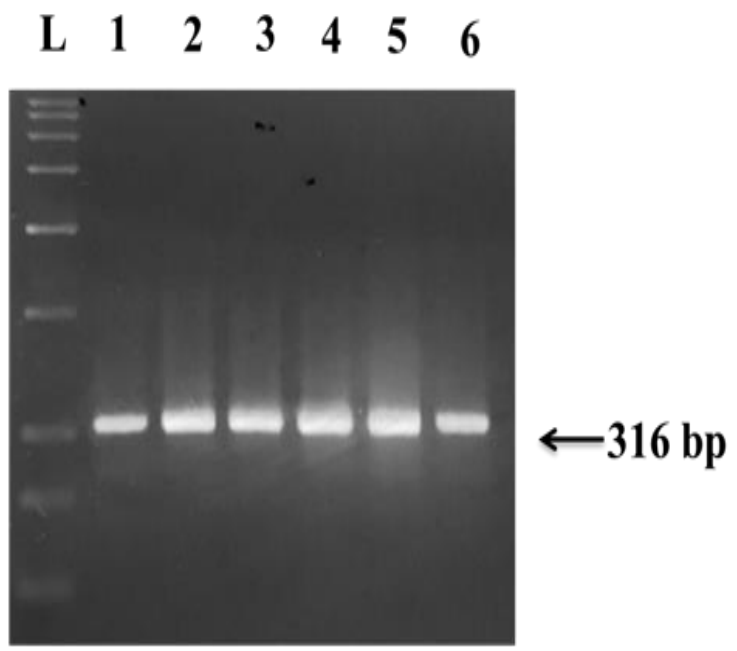

Figure 1: 2\% agarose gel electrophoresis for KCNJ11 PCR product.

L-100bp DNA ladder

1-6: PCR Product of $316 \mathrm{bp}$

KCNJ11 polymorphism(6956A $>$ G) was identified by using 6 ul PCR product with 2.5 units of restriction enzyme Hpy188III (NEB) incubated for overnight at $37^{\circ} \mathrm{C}$. Hpy188III recognises 
the sequence-TCG; digesting the PCR product to yield 218bp and 98bp DNA fragments. The wild type allele (A/A) yielded 1 band of $316 \mathrm{bp}$; Heterozygous (A/G) yielded 3 bands of 316bp, 218bp and 98bp and mutant allele (G/G) yielded 2 bands of $218 \mathrm{bp}$ and 98bp. Digested PCR products subjected to electrophoresis in a 3\% agarose gel as shown in Fig.2.

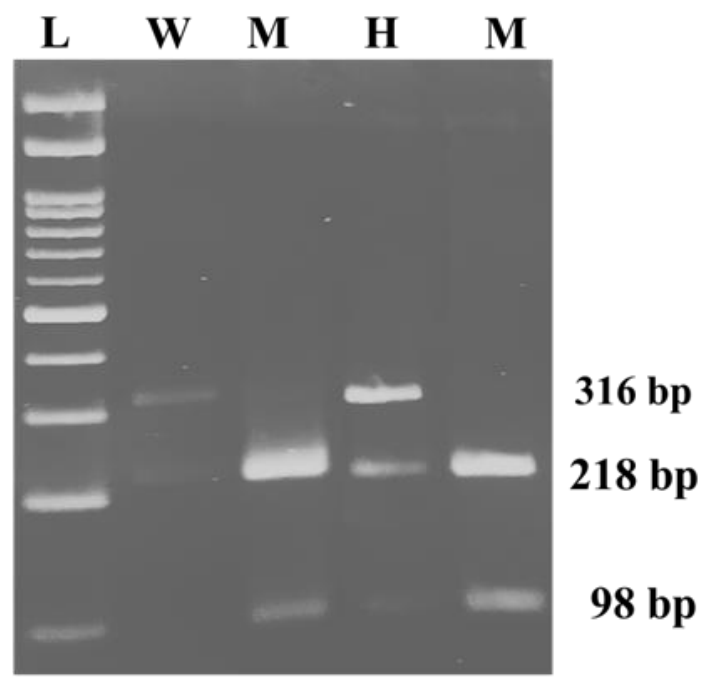

Figure 2: 3\% Agarose gel electrophoresis for digested PCR product.

\author{
L-100bp DNA ladder \\ M- Homo Mutant (G/G) \\ H- Hetero $(\mathrm{A} / \mathrm{G})$ \\ W-Homo Wild (A/A)
}

\title{
4.3 Statistical Analysis
}

We used the SPSS Software (21.0 version, IBM, United States). Chi square test was applied for comparing genotype and allele frequencies for statistical significance between diabetic patients and controls. The Hardy-Weinberg equilibrium (HWE) was measured using the $\chi^{2}$ test for goodness of fit. Comparative analysis of clinicopathologic characteristics between cases and control was performed by student t-test for equality of means. Level of significance was set at $95 \%$ (i.e. $\mathrm{p}<0.05$ ). 


\section{Conclusion}

We identified significant association of KCNJ11 (rs5210) gene polymorphism with T2DM risk in North Indian patients suggesting the role of this variant in increased risk of developing T2D in North Indian population. However, a large cohort study is required to validate the expression of these genes in diverse populated country like India.

Author Contributions Conceptualization, MYS and KD; Data curation, VK, DB and SK; Formal analysis, VK, AKV, SR and YG; Methodology, VK and SK; Software, DB; Supervision, KD; Validation, RH; Visualization, MYS; Writing - original draft, VK, DB and SK; Writing - review \& editing, PSB, MAA, AHR and KD.

Funding: There was no funding for this study.

Acknowledgments: We would like to acknowledge all the study participants who were included in this study. VK would like to acknowledge DBT for providing Fellowship, under DBT JRF/SRF scheme.

Conflict of Interest: The authors declare no conflict of interest

\section{Ethical approval \& consent to participate}

Institutional Ethics Committee of Jamia Millia Islamia (Proposal No. 17/9/14/JMI/IEC/2015 dated 14/01/2016) approved this study. A written informed consent was obtained before inclusion in the study.

\section{Abbreviations}

IDF: International Diabetes Federation

KCNJ11: Potassium inwardly-rectifying channel, subfamily J, member 11

GWAS : Genome-wide association studies

SUR1: Sulfonylurea receptor 1

KATP : ATP- sensitive K channel

OR: Odds ratio

CI: Confidence interval 
HWE - Hardy-Weinberg equilibrium

SNP: Single nucleotide polymorphism

\section{References}

1. Sluik D, Boeing H, Li K, Kaaks R, Johnsen NF, Tjønneland A, et al. Lifestyle factors and mortality risk in individuals with diabetes mellitus: are the associations different from those in individuals without diabetes? Diabetologia. 2014;57(1):63-72.

2. Yasuda K, Miyake K, Horikawa Y, Hara K, Osawa H, Furuta H, et al. Variants in KCNQ1 are associated with susceptibility to type 2 diabetes mellitus. Nature genetics. 2008;40(9):1092.

3. Voight BF, Scott LJ, Steinthorsdottir V, Morris AP, Dina C, Welch RP, et al. Twelve type 2 diabetes susceptibility loci identified through large-scale association analysis. Nature genetics. 2010;42(7):579.

4. Yamauchi T, Hara K, Maeda S, Yasuda K, Takahashi A, Horikoshi M, et al. A genome-wide association study in the Japanese population identifies susceptibility loci for type 2 diabetes at UBE2E2 and C2CD4A-C2CD4B. Nature genetics. 2010;42(10):864.

5. Chauhan G, Spurgeon CJ, Tabassum R, Bhaskar S, Kulkarni SR, Mahajan A, et al. Impact of common variants of PPARG, KCNJ11, TCF7L2, SLC30A8, HHEX, CDKN2A, IGF2BP2, and CDKAL1 on the risk of type 2 diabetes in 5,164 Indians. Diabetes. 2010;59(8):2068-74.

6. Gloyn AL, Pearson ER, Antcliff JF, Proks P, Bruining GJ, Slingerland AS, et al. Activating mutations in the gene encoding the ATP-sensitive potassium-channel subunit Kir6. 2 and permanent neonatal diabetes. New England Journal of Medicine. 2004;350(18):1838-49.

7. Aguilar-Bryan L, Bryan J. Molecular biology of adenosine triphosphate-sensitive potassium channels. Endocrine reviews. 1999;20(2):101-35.

8. Haghvirdizadeh P, Mohamed Z, Abdullah NA, Haghvirdizadeh P, Haerian MS, Haerian BS. KCNJ11: genetic polymorphisms and risk of diabetes mellitus. Journal of diabetes research. 2015;2015.

9. McTaggart JS, Clark RH, Ashcroft FM. SYMPOSIUM REVIEW: The role of the KATP channel in glucose homeostasis in health and disease: more than meets the islet. The Journal of physiology. 2010;588(17):3201-9.

10. Florez JC, Burtt N, De Bakker PI, Almgren P, Tuomi T, Holmkvist J, et al. Haplotype structure and genotype-phenotype correlations of the sulfonylurea receptor and the islet ATP-sensitive potassium channel gene region. Diabetes. 2004;53(5):1360-8.

11. Barroso I, Luan Ja, Middelberg RP, Harding A-H, Franks PW, Jakes RW, et al. Candidate gene association study in type 2 diabetes indicates a role for genes involved in $\beta$-cell function as well as insulin action. PLoS biology. 2003;1(1):e20.

12. Qin L, Lv Y, Huang Q. Meta-analysis of association of common variants in the KCNJ11-ABCC8 region with type 2 diabetes. Genet Mol Res. 2013;12(3):2990-3002.

13. Yang L, Zhou X, Luo Y, Sun X, Tang Y, Guo W, et al. Association between KCNJ11 gene polymorphisms and risk of type 2 diabetes mellitus in East Asian populations: a meta-analysis in 42,573 individuals. Molecular biology reports. 2012;39(1):645-59.

14. Koo B, Cho YM, Park B, Cheong H, Shin H, Jang HC, et al. Polymorphisms of KCNJ11 (Kir6. 2 gene) are associated with Type 2 diabetes and hypertension in the Korean population. Diabetic Medicine. 2007;24(2):178-86. 
15. Willer CJ, Bonnycastle LL, Conneely KN, Duren WL, Jackson AU, Scott LJ, et al. Screening of 134 single nucleotide polymorphisms (SNPs) previously associated with type 2 diabetes replicates association with 12 SNPs in nine genes. Diabetes. 2007;56(1):256-64.

16. Cruz M, Valladares-Salgado A, Garcia-Mena J, Ross K, Edwards M, AngelesMartinez $\mathrm{J}$, et al. Candidate gene association study conditioning on individual ancestry in patients with type 2 diabetes and metabolic syndrome from Mexico City. Diabetes/metabolism research and reviews. 2010;26(4):261-70.

17. Khan IA, Vattam KK, Jahan P, Mukkavali KK, Hasan Q, Rao P. Correlation between KCNQ1 and KCNJ11 gene polymorphisms and type 2 and post-transplant diabetes mellitus in the Asian Indian population. Genes \& Diseases. 2015;2(3):276-82.

18. Keshavarz P, Habibipour R, Ghasemi M, Kazemnezhad E, Alizadeh M, Omami $\mathrm{MHH}$. Lack of genetic susceptibility of KCNJ11 E23K polymorphism with risk of type 2 diabetes in an Iranian population. Endocrine research. 2014;39(3):120-5.

19. Čejková P, Novota P, Černá M, Kološtová K, Nováková D, Kučera P, et al. KCNJ11 E23K polymorphism and diabetes mellitus with adult onset in Czech patients. Folia Biologica (Praha). 2007;53:173-5.

20. Benrahma H, Charoute H, Lasram K, Boulouiz R, Atig RK-B, Fakiri M, et al. Association analysis of IGF2BP2, KCNJ11, and CDKAL1 polymorphisms with type 2 diabetes mellitus in a Moroccan population: a case-control study and meta-analysis. Biochemical genetics. 2014;52(9-10):430-42.

21. Odgerel Z, Lee HS, Erdenebileg N, Gandbold S, Luvsanjamba M, Sambuughin N, et al. Genetic variants in potassium channels are associated with type 2 diabetes in a Mongolian population. Journal of diabetes. 2012;4(3):238-42. 